\title{
SALVADOREÑAS DIVINAS en Ciudad JuÁrez
}

\author{
Divine Salvadorans in Juarez
}

NITHIA CASTORENA SÁENZ1

Para Brittany, por su tiempo y su confianza.

\section{RESUMEN}

\begin{abstract}
O e presenta la historia de vida de una mujer trans migrante S centroamericana que, junto con otras, busca llegar a Estados Unidos, pero debió establecerse temporalmente en Juárez por la pandemia. Para el análisis se plantea tanto un modelo de exclusiones titulado Orden de Vitruvio, que implica la operación múltiple e interseccional de distintos criterios que derivan en formas de exclusión agudas, así como una propuesta de análisis localizado, con la historia reciente de El Salvador. Finalmente, el texto concluye que es la colectividad una apuesta política y estratégica de resistencia frente a la operación del orden de Vitruvio.
\end{abstract}

Palabras clave: trans, migrantes, colectivo, poder, resistencia

1 Universidad Autónoma de Chihuahua. Correo: castorenasaenz@gmail.com 


\begin{abstract}
The life story of a Central American trans migrant woman is presented whom, along with others, seeks to reach the United States but has had to temporarily settle in Juárez due to the pandemic. For the analysis, a model of exclusions entitled Vitruvian Order is proposed, which implies the multiple and intersectional operation of different criteria that lead to acute forms of exclusion, as well as a proposal for a localized analysis that links with the recent history of El Salvador. Finally, the text concludes that the collectivity is, as well, a strategy and a political commitment to resistance against the operation of the Vitruvian Order.
\end{abstract}

Key words: trans, migrants, collective, power, resistance

\title{
PUNTOS DE PARTIDA. A MODO DE INTRODUCCIÓN
}

Juárez es, de múltiples formas, un lugar de fronteras. Siguiendo las reflexiones de Sassen (2003) al respecto de la ciudadanía en circuitos transfronterizos se verá actualizado, en el caso de Juárez, el encuentro entre las personas sin poder y aquellas que sí lo tienen. Así, las fronteras no solo son entre países, sino entre personas: locales y foráneas, mujeres y hombres, ricas y pobres, con y sin estudios, con y sin visa para cruzar a El Paso, entre otras diferencias que, de múltiples formas, provocan exclusión.

Lo que este artículo compartirá es un caso más de estos encuentros. Cuando Deleuze y Guattari (2015) escriben: "Dado que cada uno de nosotrxs era varios, había ya toda una multitud" ${ }^{2}$ ( . $^{2}$ 9) invitan a considerar las formas múltiples, rizomáticas, en las que las personas nos forman y nosotrxs formamos a otras personas. En roces, cruces, relaciones, miradas a los ojos o completas omisiones. Esto es, por supuesto, una configuración ontológica y

2 Traducción propia de la versión en inglés: "Since each of us was several, there was already quite a crowd”, (2015) Mil mesetas. Capitalismo y esquizofrenia, PreTextos, Valencia, pág. 9. 
ética que sitúa en su justa dimensión las relaciones humanas y que deriva en múltiples y constantes formas de ser en y con el mundo. El artículo aborda un primer análisis de la situación de un grupo de mujeres trans migrantes centroamericanas que radicaron en Juárez por más de un año, en espera de consumar su migración hasta su destino último: Estados Unidos. Por lo tanto, en el texto se ofrecerán propuestas teóricas que contribuyan a analizar las múltiples exclusiones sufridas por este grupo, así como un breve estado de la cuestión respecto a El Salvador y su política interna y económica que contribuya a dimensionar las razones de una migración como última opción en la búsqueda de una vida digna.

El contexto político no podría ser más abrumador para este grupo de mujeres. En los últimos años resulta llamativo que a nivel mundial grupos de personas con ideologías conservadoras y de ultraderecha, cada vez más agresivas y radicales, ${ }^{3}$ se abrazan a los esencialismos biológicos que parecían haberse superado. ${ }^{4}$ Respecto al repunte de visiones conservadoras, no es ocioso apuntar que parten de categorías biológicas profundamente estrechas y limitadas que se relacionan, sobre todo, con percepciones superficiales del cuerpo de cada persona y buscan clasificarle de acuerdo a este y a las formas en que este se ajuste a los estereotipos que defienden.

En el ánimo de esta premisa, y como punto de partida, se busca que este texto contribuya a reflexionar sobre las formas en que las relaciones humanas potencian o coartan la emergencia del ser, ${ }^{5}$ y aseguran o arriesgan su permanencia en el tiempo. Partien-

3 Por ejemplo, los grupos organizados por Louis Beam en Texas. Para más, escúchese The Modern White Power Movement, programa de la productora NPR, disponible en: https://open.spotify.com/episode/5I4FGD0FPIWDgI9OKCnIt2?si=dgidIC1IR0WzHYTqO YVkEw

4 Aunque se abundará en este punto más adelante, es oportuno partir de una reflexión que, aunque representante de la colonialidad, ha sido parte de la formación de muchas corrientes de estudio feministas y de estudiosas de feminismos: Simone de Beauvoir escribió: "No se nace mujer: se llega a serlo. Ningún destino biológico, psíquico o económico define la figura que reviste en el seno de la sociedad la hembra humana; es el conjunto de la civilización el que elabora este producto intermedio entre el macho y el castrado al que se le califica femenino" (De Beauvoir, 2012, p. 207).

5 Se asume esta "emergencia del ser" como una especie de nacimiento que se actualiza siempre que el entorno lo permite, es decir, la influencia del contexto como un espa- 
do de la idea de que las "relaciones humanas" son una cuestión que se actualiza en cada momento del día, interesan aquí particularmente aquellas de amistad y camaradería que terminan por constituirse en una especie de colectivo de cuidados y gestión de la seguridad, en el que se construyen estrategias de auto sustentabilidad, así como de apoyo mutuo en la transformación.

Es oportuno anotar que, respecto al uso de la "x" para sustituir el femenino o masculino, amén de que la Real Academia de la Lengua Española (RAE) no lo acepte como una forma de referirse tanto a hombres como mujeres, en este trabajo el uso de la " $\mathrm{x}$ " implica no una estrategia gramatical sino, y sobre todo, refiere una forma de mover del centro a un alter ego universal masculino, que más adelante se desarrollará utilizando como "detonador simbólico" la imagen de el Hombre de Vitruvio.

Así pues, el uso de la "x", aquí, es una postura política que busca hacer evidente que son muchas las personas que no se encuentran incluidas al referir un sujeto, plural o individual, masculino. ${ }^{6}$ Aunado a esto, es oportuno anotar que el uso de la " $\mathrm{x}$ " no implica solamente la inclusión del femenino o masculino, como una forma de reducción dicotómica a uno u otra, implica "él", "ella" y "elle", este último como se describen las personas no binarias y todas aquellas posibilidades del ser que pudieran surgir.?

Por último, las reflexiones que aquí se comparten son parte de un proyecto de investigación más amplio titulado Un modelo de nombrar. Resistencias ante el devenir nada. Este busca contribuir a la construcción de estrategias de resistencia al embate de un modelo económico neoliberal y deshumanizante que fragmenta a las sociedades, los pueblos y las culturas, mermando su potencia de ver y nombrar aquello de lo que son parte (personas, situaciones y espacios).

cio de enunciación que permite esta emergencia.

6 Incluso el femenino, como desarrollaré más adelante, pero en esta parte me interesa ser más sucinta en las definiciones pues son, apenas, un punto de partida para la discusión que me interesa poner sobre la mesa.

7 Para más, véase: Kobabe, M. (2020) Género queer. Una autobiografía, Astronave, Barcelona. 
Dicha investigación analiza las formas en que opera la exclusión de personas trans, sin propiedades y migrantes. Específicamente en el caso de un grupo de personas albergadas en Ciudad Juárez, en un espacio al que huyeron después de sortear múltiples adversidades; todo ello en medio de una pandemia de escala global sin precedentes en nuestra historia reciente.

El caso particular que se aborda en este texto refiere a un grupo de amigos que hasta ese momento se asumían como gay y que concluyen, colectivamente, la posibilidad de migrar. Sin proponérselo de ese modo, esa alianza no solo resolvió cuestiones pragmáticas y logísticas del camino que estaban por emprender, sino que potenció el devenir mujeres, posibilidad que era impensable en El Salvador, pues lo identifican como un país profundamente transfóbico, en el que la única posibilidad para una mujer trans es dedicarse a la prostitución, y ese es un trabajo que no deseaban realizar. Aunado a esto, juntas debieron resolver situaciones de hostigamiento y maltrato en una de sus posadas en Juárez, así como enfrentar la vida inmovilizadas, sin poder llegar al destino que se propusieron, debido a la pandemia derivada de COVID-19. Todo esto, además, en un contexto migratorio sumamente complicado por las políticas adoptadas por Estados Unidos y México para inhibir el flujo de personas.

Es oportuno anotar que en este texto se abordan las experiencias trans desde una perspectiva epistemológica en la que estas son parte de relaciones múltiples y multiestratificadas entre transformación y devenir, no solo de sujetos en lo individual, sino a partir de sus relaciones con pares, con sus familias y con el mismo contexto geopolítico e histórico en el que se encuentran.

En cuanto al proyecto de investigación amplio, este parte de la idea de que el referente de lo humano, una especie de alter ego universal, o sea de un modelo universal del ser, es el que determina las diversas expulsiones de la escena pública y del ejercicio de derechos de todos aquellos sujetos que no cumplan con lo que dicho alter ego establece. La imagen que mejor lo representa es la 
pieza de Leonardo Da Vinci Hombre de Vitruvio que aquí se utiliza para representar a aquel que es hombre, blanco, heterosexual, que tiene propiedades a su nombre, que pertenece a la sociedad occidentalizada (o sea, a una semiosfera hegemónica y hegemonizante al interior, y con ejercicio de poder hacia el exterior) y que vive donde nació. Todo esto configura la posibilidad de reconocimiento social, público, aquel en el que es posible que la gente les conozca, y al conocerles y reconocerles, en los espacios públicos y privados, les nombran, les refieren con un nombre en particular; incluso el Estado les reconoce formalmente su existencia, a través un acta de nacimiento, por ejemplo. Es oportuno anotar que este orden de Vitruvio, como representación de un alter ego universal con un hombre al centro, genera con su fuerza (y abuso de poder) un espacio de enunciación (Spivak, 2003) estrecho en el que no puede participar ningún sujeto que no cumpla cada una de las categorías anteriormente referidas. Obviamente esta no es una acción individual, sino que es una operación conjunta e interrelacionada de los dispositivos de tres grandes sistemas: patriarcal, capital y colonial. Esto implica que existe toda una traza de siglos (y símbolos) ulteriores en los que no hay nadie si no hay un hombre blanco heterosexual occidental reconocido y con propiedades. ${ }^{9}$

8 El Hombre de Vitruvio fue plasmado por Leonardo Da Vinci alrededor de 1490. La imagen es icónica de por sí, albergada en las Galerías de la Academia de Venecia. El dibujo fue encontrado en el diario del pintor y contiene, además del título aquí referido, el de "Estudio de las proporciones ideales del cuerpo humano". Según la Dra. Joanne Allen, Profesora Senior en el Departamento de Arte de la Universidad Americana, este es "un dibujo muy inusual de Leonardo", "un dibujo muy bien elaborado con pluma y tinta, completado para expresar una noción intelectual concisa, no un sketch de una observación científica o un dibujo preparatorio para pintura" (British Broadcasting Corporation [BBC], 2019).

9 Véase por ejemplo, la polémica desatada con el asesinato de dos jóvenes argentinas (2016), que viajaban por Ecuador, los titulares del homicidio versaban sobre las consecuencias de "viajar solas"; la premisa inherente en dichos encabezados es que la compañía mutua que se hacían ambas jóvenes no contaba como una presencia (Para ver más: https://www.bbc.com/mundo/noticias/2016/03/160304_america_latina_turistas_argentinas_montanita_ecuador_viajosola_ppb ). Por lo tanto, la forma de no estar sola es tener a un hombre blanco consigo, y preciso que es necesario el hombre blanco (con poder y reconocimiento, tanto social como del Estado) pues un hombre indígena o de ascendencia africana no sería tomado en cuenta como un "ser completo", tal como lo retrata Rosario Castellanos en su novela Balún Canán, con las ausencias del señor Argüello de la Hacienda. 
Es oportuno anotar que cuando se habla de propiedades estas refieren al hecho de que en el marco de conformación de los estados nacionales, a través de ellas, se asignó la condición de ciudadanía, excluyendo por tanto a buena parte de la población. Otros mecanismos de "ciudadanización" correspondieron con levas y servicios militares que inculcaron "valores" y hábitos considerados civilizados, muchos de los cuales se vieron representados en la construcción del alien como documentó Carlos González Herrera (2008).

El planteamiento de la operación del ejercicio de poder de este hombre de Vitruvio se construye en analogía a una de las fuerzas que estudia la física: la fuerza centrífuga. De este modo, cuando este gira sobre su propio eje, expulsa hacia el exterior a todos los sujetos que no cumplen con las características de sí mismo. Dicha exterioridad es lo que conceptualmente se propone como devenir nada, entendido este espacio como aquel en el que una persona deja de ser un sujeto de derechos a los ojos del Estado. Devenir nada no implica que los sujetos dejen de existir (ontológicamente hablando) sino, más bien, que sus vidas dejan de importar (Butler, 2006).

Esta expulsión del centro puede explicarse como una actuación en capas formadas por círculos concéntricos alrededor de la figuran de un hombre de Vitruvio, y que aquí propongo llamar Orden de Vitruvio. Aunque la operación de expulsiones puede ocurrir de formas simultáneas, en el caso particular de este texto, se sugiere una secuencia de expulsiones como la siguiente: arrojadas en la primera expulsión están las mujeres (cis y trans) y cualquier sujeto leído como femenino o feminizado (travestis, homosexuales, hombres trans, de género no binario, queer, entre otros). En el segundo círculo se encuentran las personas con una orientación sexual no heterosexual y/o no binaria. El tercero representa a las personas pobres, precarizadas, sin propiedades ni privilegios económicos o de redes, alianzas, contactos. En el cuarto círculo se encuentran las personas que no habitan el espacio geográfico en el que nacieron/crecieron, partiendo de la idea de que cuando ocurre de ese modo, que se ocupa el espacio en 
el que se nació, hay un reconocimiento tácito del ser que se es y contará con los atributos mínimos de reconocimiento por parte del Estado, como un acta de nacimiento o identificación oficial. La última órbita implica a las personas de semiosferas (Lotman, 1996) particulares que muy pocas personas comprenden, como los pueblos indígenas.

Ahora bien, que los sujetos que no cumplen con el estereotipo establecido por el alter ego universal sean expulsados del espacio de reconocimiento no implica que permanezcan inmóviles frente a estas fuerzas de expulsión, desamparadxs, solo esperando la acción de la potencia que habrá de expulsarles: operan resistencias. Para efectos de esta investigación interesan las formas en que dichas resistencias puedan presentarse tanto de formas evidentes como sutiles (Scott, 2005).

Es oportuno anotar que las resistencias serán activadas por las personas que han sido "removidas del centro", con la intención de volver a este y tener así el reconocimiento social y del Estado, que el hombre de Vitruvio tiene garantizado por el solo hecho de respirar. Para identificar dichas resistencias es necesario ubicar los dispositivos que "expulsan" a estos sujetos en cada una de las órbitas. Para ello, es oportuno lo expuesto por Giorgio Agamben, respecto a la definición del dispositivo como un "conjunto heterogéneo, que incluye virtualmente cualquier cosa, lingüístico y no lingüístico al mismo nivel: discursos, instituciones, edificios, leyes, medidas policiales, proposiciones filosóficas, etc. El dispositivo es en sí mismo la red que se establece entre estos elementos" (Agamben, 2015, p. 11).

De este modo, cada una de las órbitas que ayudan a explicar las expulsiones de estos sujetos devenidos nada tendrán sus propios dispositivos para lograr que la expulsión se consume y abrevarán de las expulsiones que precedan o alimentarán futuras expulsiones. ${ }^{10}$ En el caso de la primera órbita, aquella que ubica

10 Estas expulsiones no son graves solamente porque impidan un ejercicio integral de los derechos que el Estado supone garantizar, sino que pueden ser consideradas análogas de las que Feinstein establece como fases hacia el genocidio, femigenocidio en este caso, "el genocidio no es simplemente un acto exterminador aislado [...] sino un proceso paulatino de destrucción de los sujetos y deshumanización de las vícti- 
a las mujeres y sujetos feminizados, el dispositivo que les expulsa del centro se compone de todas las expresiones de la misoginia, entendida como una operación constante, que abarca todos los intersticios de la vida pública y privada, que no es conscientemente organizada pero sí reiterada, firme y públicamente reproducida para privilegio masculino; ${ }^{11}$ permite a los hombres imponerse, conservar y afianzar aquello que consideran propio (reconocimiento público, valor, certidumbre económica, inteligencia, fuerza) y establecer así su dominio; aquí estarían todas las expresiones de violencia sistémica y sistemática hacia las mujeres: omisiones, acoso, agresiones, violaciones, feminicidios, así como todas aquellas acciones y expresiones que consolidan y consuman el sistema patriarcal.

En cuanto a la segunda órbita, compuesta por las personas con una orientación sexual no heterosexual y/o no dicotómica, el dispositivo estaría compuesto por todas las expresiones de la homofobia, lesbofobia y aquellas que pudieran configurar el principio de discriminación y violencia hacia estos grupos. El centro, ese hombre de Vitruvio, es, como se mencionó antes, profundamente heteronormado.

Es oportuno incorporar una breve discusión a este respecto: uno de los argumentos más recurrentes de grupos y corrientes de derecha y ultraderecha, respecto a la homosexualidad y el lesbianismo, tiene que ver con el hecho de no poder reproducirse entre personas del mismo sexo. Así, este es su argumento más fuerte en contra de cualquier tipo de relación no-heterosexual: el de la imposibilidad de reproducción. Es oportuno anotar al respecto que la industria genética y de reproducción asistida ha cristalizado con singular éxito en los últimos años, y no como una labor filantrópica para las parejas del mismo sexo o para aquellas parejas con

mas hasta llegar a su exterminio físico"; para más, véase: https://www.jornada.com. $\mathrm{mx} / 2013 / 05 / 11 /$ oja-fases.html

11 Al respecto, Sayak Valencia ofrece que: "el movimiento transfeminista busca evidenciar que la masculinidad (como ficción política viva) es un dispositivo de implementación y conservación de un proyecto de modernidad/colonialidad y nación que en su transformación está ligado al surgimiento y actualización de la economía capitalista”, en (Valencia, 2020). 
problemas de fertilidad, sino por la gran plusvalía que generan. Una búsqueda sencilla en internet, desde una dirección IP mexicana, arroja alrededor de 1670000 páginas de clínicas y medios de comunicación que abordan el tema de reproducción en parejas homosexuales y lesbianas en México, Estados Unidos y España.

Por otra parte, y respecto a lo que implica el caso particular de personas trans, dentro de la enorme cantidad de producción teórica de lo trans en los últimos 30 años, y sin -obviamente intentar agotarla en este espacio, es pertinente atraer a Raewyn Connell por el término que ella desarrolla: "masculinidad hegemónica”. A partir del cual establece una precisión que es esencial: masculinidades no son hombres, sino que la masculinidad es una posición que se ocupa al interior de una estructura mayor que es el género. De tal forma que se convierte en una posición que es performativa y que implica poder. Ahora bien, es oportuno adelantar lo problemático de la noción de género, es decir, es posible considerar que la diferencia entre sexo y género se ha tornado en un espacio de comodidad, pues el género permite la idea de las construcciones histórica y culturalmente aprehendidas, mientras que el sexo se había asumido como lo inamovible, objetivo y natural, "puro". ¿Es así en verdad?, ¿no estaríamos ya en un momento de las reflexiones en el que tendríamos que aceptar que el sexo es también una noción aprehendida cultural e históricamente y que, por tanto, podría ser modificada y transformarse a lo largo de una vida? Es oportuno recordar que la biología como destino ha sido debatida desde mediados del siglo xx por los grupos feministas, y ahora, un grupo de mujeres confundidas que se dicen feministas ha reivindicado la biología hasta el extremo ridículo de considerar mujeres solo a las que tienen útero, ¿no sería esa una definición vergonzosamente biologicista?

En la filosofía producida por personas trans también se presentan algunas tensiones, por ejemplo, entre Miquel Missé y Siobhan Guerrero. El primero propone una idea de "robo del cuerpo" para explicar lo que les ocurre a las personas trans que entran en los espacios médicos, clínicos, estéticos para consumar ahí su transformación, toda esta narrativa abona a esa premisa originaria del 
test de disforia de género: "que naciste en un cuerpo equivocado" y que la única forma de recuperarlo es intervenirlo (hormonal y quirúrgicamente), y en esa operación ocurre una especie de "expropiación" del cuerpo del sujeto trans para serle entregado al discurso médico. Por su parte, Guerrero resalta el esencialismo material y ontológico de Missé, quien propone que ninguna intervención, ni quirúrgica ni hormonal, debería hacerse a los cuerpos trans, en el ánimo de que estos se conservaran como propios y no entregados a esas narrativas. La filósofa concluye que en el intento de Missé de huir de un esencialismo ha caído en otro.

Por último, en esta breve discusión intermedia, me interesa anotar al menos el interés de seguirla a partir de lo que propone Gilles Deleuze en Diferencia y repetición, cuando plantea que la relación $A-B$ existe, independientemente de $A$ y de $B$, o sea, la relación es un tercer sujeto, independiente de los puntos que relaciona (Deleuze, 2002); de este modo, las personas trans moldeadas y formadas, también, por todas las relaciones que las interpelan, con su transición estarían impactando no solo a sí mismas, sino a las relaciones de las que son parte. Como queda claro, las posibilidades de la idea de relación en Deleuze son enormes, por ejemplo, si esa relación con el sujeto, previamente a su transformación, ya existía, cómo se impactaría a partir de la transformación. Suponiendo que el sujeto trans es A y que su contexto es B. Lo quiera A, o no lo quiera; lo quiera B, o no lo quiera; la relación A-B existe. ¿Qué pasa luego de la transformación?, ¿sería posible considerar una especie de A'-B?

Ahora, retomando la presentación de las órbitas, la tercera corresponde a las personas pobres, precarizadas, sin propiedades ni privilegios económicos o de relaciones que les beneficien económicamente; el dispositivo que opera en contra de este grupo se conforma por la aporofobia (Cortina, 2017) y es la operación de una sociedad clasista y racista que regulará y mantendrá en juicio perpetuo la "blanquitud" de los sujetos sospechosos (Echeverría, 2010). ${ }^{12}$ Esta órbita se encuentra expresada en México, en todo

12 Bolívar Echeverría plantea que es posible "llamar blanquitud a la visibilidad de la identidad ética capitalista en tanto que está sobredeterminada por la blancura racial, pero 
un sistema clasista que, aunque fundamentado sobre todo en el dinero y la acumulación, va más allá de este a una configuración de redes familiares, de amistades y laborales.

La cuarta órbita se representa por las personas que no habitan en el espacio geográfico en el que nacieron o crecieron, o sea, migrantes. En la actualidad la migración como circunstancia de muchas personas ha sido severamente condenada tanto formal como socialmente. Parto del supuesto de que las personas migrantes migran precisamente como una estrategia de volver al espacio de reconocimiento a través de la ampliación de oportunidades tanto educativas como económicas (aunque, sobre todo estas últimas). Al hacerlo, sacrifican la visibilidad que tenían en su lugar de origen, al menos la del Estado: un acta de nacimiento, una nacionalidad; ${ }^{13}$ además, ponen en riesgo sus vidas y su integridad, pues esta se ve amenazada por todo lo que puede ocurrirles en el trayecto, sin embargo, migración no implica en absoluto liberación de un modelo económico, pues migran sobre todo para poder trabajar, es decir, arriesgan su vida para mantener la producción y con ella la plusvalía se ve intacta. El sistema capitalista, en este acto, no solo permanece, sino que se consolida. Eso ayudaría a comprender, por ejemplo, que el caso del asesinato de 72 migrantes en San Fernando, Tamaulipas, siga impune hasta

por una blancura racial que se relativiza a sí misma al ejercer esa sobredeterminación [...] Es la compostura de los personajes, una compostura que denota blanquitud, y no blancura de raza, lo que impresiona en la representación de la nueva dignidad humana que hay en los numerosos retratos de burgueses u hombres modernos de la pintura flamenca en los siglos xv y xvi” (Echeverría, 2010, p. 62).

13 Es pertinente anotar aquí una participación de Judith Butler en una conversación con Gayatri Spivak, pues ofrece algunos puntos de partida importantes respecto al concepto de Estado que es necesario desarrollar para la investigación. En dicha ocasión, Butler afirma que "El estado define la estructura legal e institucional que delimita cierto territorio [...] Por lo tanto, se supone que el estado sirve de matriz para los derechos y obligaciones del ciudadano, lo cual define las condiciones por las cuales estamos vinculados jurídicamente [...] desde el momento en que el estado puede ser precisamente aquello que expulsa y suspende modos de protección legal y deberes, el estado mismo puede ser, para muchos de nosotros, causa de malestar. Puede definir la fuente de no-pertenencia, incluso producir la no-pertenencia como un estado casi permanente" (Butler y Spivak, 2009, p. 44). Por su parte, Virginie Despentes afirma que "El poder que otorga un estado enfermo es forzosamente un poder sospechoso" (Despentes, 2018, p. 31). 
la fecha. No hay ningún interés en su resolución pues no impactó (ni entonces, ni ahora) en el sistema económico. Como menciona Sayak Valencia:

El sistema capitalista es la muestra de la quiebra del sistema de trabajo, de la radicalización obscena del liberalismo, del devenir gore del sistema económico, y también la forma visible aún persistente y ampliamente aceptada donde se articulan la opresión machista, el expolio, la muerte y la violencia contra los que históricamente han sido considerados minoritarios (Valencia, 2020, p. 8).

Por último, la quinta órbita es donde se encuentran las personas que pertenecen a una semiosfera (Lotman, 1996) que es poco comprendida y/o conocida, que es justo el caso de los pueblos originarios. El dispositivo que les expulsa se conforma de una mezcla de racismo ${ }^{14}$ y clasismo, que desprecia todo aquello que desconoce y a lo que le coloca en una posición de subalternidad. Redes de símbolos operan en concierto para este fin, el desprecio no es un acto individual y aislado, sino sistemático, organizado, aprendido y aprehendido en cada etapa de la vida familiar y social. Aunque es necesario profundizar aún más a este respecto, por lo pronto interesa dejar anotado que esta idea presenta una especie de codependencia entre sistemas excluyentes. Es decir, el racismo es necesario en un sistema capitalista, pues opera también como un sistema multiestratificado y simbólico que parte de la idea de una inferioridad por razones de origen, autoadscripción o ascendencia. El desprecio y la subvaloración de grupos de personas, como las negras y las pertenecientes a pueblos originarios, le permiten al capital lucrar y obtener una ganancia económica, infravaluando su trabajo, sus capacidades, sus derechos.

14 Es oportuna la anotación que hace Waquel Drullard al respecto: "el racismo no es un comportamiento, una expresión o un gesto de desigualdad social, sino una experiencia que jerarquiza vidas [...] colocando a las vidas blancas como dueñas de la humanidad y a las vidas pobres, racializadas, periféricas y desbordadas en las orillas del mundo, como vidas no válidas e impensables para ser consideradas humanas" (Drullard, 2020, s.p.). 
Del mismo modo, el patriarcado (Lerner, 1986) alimenta a un sistema capitalista, exigiendo de las mujeres la realización de una serie de trabajos gratuitos y sin reconocimiento como el cuidado de otrxs, la elaboración de alimentos, administración del hogar, traslado de personas, cuidado de personas enfermas o adultas mayores, cuidado de otros seres vivos como animales y plantas, responsables de conciliación y solución de conflictos al interior del hogar, entre otras; amén del lucro que implica la explotación de los cuerpos de las mujeres a través de la violencia y la trata de personas. ${ }^{15}$

Incluso la órbita relacionada con habitar el espacio en el que se nació, y que implica directamente a las personas migrantes, ofrece un panorama complejo y también supeditado en parte al sistema capitalista pues, como se comentó en párrafos anteriores, las personas migran sobre todo para poder trabajar y este trabajo, el de sus cuerpos, cuerpos de personas migrantes que arriesgaron su vida para poder realizarlo, se traducirá en la plusvalía que el capital requiere para seguir existiendo.

\section{EL SALVADOR, EL ESLABÓN MÁS PEQUEÑO}

\section{Todos los salvadoreños que hemos nacido después de 1932, hemos nacido medio muertos, medio vivos Roque Dalton, 1976.}

La región latinoamericana no solo refiere a un espacio geográfico particular, sino que se torna en una categoría que contribuye a la reflexión de lo que en ella ocurre. La tensión para desmarcarse de la génesis de expolio y colonialismo requerirá de análisis par-

15 La Organización de las Naciones Unidas estima en 2.5 millones el número de personas víctimas de trata, de las cuales se cree que existen 20 más por cada víctima identificada; la mitad de víctimas de trata tienen menos de 18 años, entre 15 y 20 \% son niñas y niños; dos terceras partes de las víctimas detectadas por las autoridades son mujeres, 79 \% sometidas a explotación sexual y 18 \% con fines de explotación laboral o servicios forzados; 56 \% de las personas dedicadas al tráfico humano son hombres (Reporte Global 2009, Informe de Globalización del crimen, Oficina de las Naciones Unidas contra las Drogas y el Delito). 
ticulares en ella. Como lo señala Selva-Sutter: "La relación con los Estados Unidos afecta la estabilidad política, económica y social de la región, porque es una relación de dominio neoliberal" (SelvaSutter, 2018, p. 273). Esto se ha tornado evidente en la región centroamericana a partir de la década los 70 en Nicaragua, luego en El Salvador y Guatemala con la operación de gobiernos dictatoriales, el surgimiento de movimientos armados de resistencia y la posterior represión hacia la población.

Dado que las entrevistas a mujeres trans migrantes en Juárez se realizaron sobre todo a mujeres salvadoreñas, se vuelve necesario, entonces, hacer un breve recorrido histórico de las experiencias sociales, políticas y económicas que pueden ser comunes y/o transversales para la población salvadoreña.

El Salvador, como país centroamericano, no estuvo exento de la impronta de dictaduras y violencia política durante el siglo $\mathrm{XX} .{ }^{16}$ Como se adelantó desde las premisas conceptuales de este texto, se antojan harto improbables los "fenómenos aislados", muy al contrario, estos fluctúan en un continuo de hechos y eventos que, más allá de identificarles como causas o consecuencias, es pertinente valorarles como sucesos rizomáticos en un contexto histórico y geopolítico particular.

Los intereses que se urden y consolidan con la entrada en territorio centroamericano de la United Fruit Company se encuentran con los de las burguesías guatemalteca y salvadoreña para conformar "lo que en definitiva, a partir de 1960, constituye el Mercado Común Centroamericano" (Menjívar, 2018, p. 25). Esto encuentra respuesta en el territorio mexicano con el periodo del desarrollo estabilizador, y el arranque de toda una política de descentralización y neoliberalismo a partir de 1982 durante la administración de Miguel de la Madrid. Es precisamente en esta década, la de los 80, que la frontera norte de México se va configurando en una apues-

16 Por ejemplo, puede consultarse Masacre de 1932, el mayor etnocidio de la historia contemporánea de El Salvador, disponible en: https://www.notimerica.com/cultura/noticia-masacre-1932-mayor-etnocidio-historia-contemporanea-salvador-20170129073433. html 
ta eminentemente industrial con la instalación de distintas plantas maquiladoras, principalmente de arneses en este primer periodo. ${ }^{17}$

En Centroamérica, los antagonismos políticos se radicalizaron con la misma fuerza del ostracismo gobernante, así en 1970 se forma en El Salvador el Ejército Revolucionario del Pueblo. Al fraude electoral de 1972 le sigue una oleada de represión a disidentes, con el encarcelamiento y "exilio de sus dirigentes, persecución contra sectores de la iglesia revolucionaria y del campesinado organizado" (Menjívar, 2018, p. 28).

Estos enfrentamientos en el pequeño país de Centroamérica concluyeron con "192 personas asesinadas en la primera mitad de 1979, 214 encarceladas por las mismas razones, 126 personas desaparecidas"; todo informado por la misma Comisión de Derechos Humanos de El Salvador (Menjívar, 2018, p. 29). Por su parte, en México las radicalizaciones de grupos sociales, sobre todo estudiantiles y campesinos, habían comenzado desde el 23 de septiembre de 1965 con el asalto al cuartel de Madera, en la Sierra Tarahumara de Chihuahua. De ahí se desprendieron actividades armadas en varios grupos en el país, hasta 1973 en que varios de estos buscaron unirse en la Liga Comunista 23 de Septiembre, la cual contó con grupos que operaron en Juárez a finales de la década de 1970 y principios de los 80, en los que se incluían trabajadoras de maquila, tal como lo ha documentado Alicia de los Ríos Merino (2014).

Para el 2016, El Salvador registró una tasa de 81.7 homicidios por cada 100000 habitantes, muy lejos de los 10 por cada 100000 que proyectaba como ideal la Organización Mundial de la Salud (OMS). Es oportuno resaltar la presencia de los grupos delictivos conocidos como "maras", hay autoras que consideran que la presencia y capacidad criminal de este tipo de pandillas "creció significativamente con la llegada a El Salvador, Guatemala y Honduras de miles de jóvenes pandilleros que fueron deportados de Estados Unidos durante los noventa y que culminó con la consoli-

17 Aunque la instalación de estas plantas comienza propiamente desde la década de los 60, para la década de los 80 seguía robusteciéndose como eje económico industrial en la fronteriza Juárez. 
dación de la Mara Salvatrucha (MS-13) y Barrio 18 (MS-18)" (Prado, 2018, párr. 2), principales pandillas de la región. Una cuestión más que apuntala la autora es que, para 2014, la tasa de homicidio de la región, en víctimas de 15 a 29 años, era cuatro veces superior a la del resto del mundo.

México y el estado de Chihuahua no eran una excepción en cuanto a la situación de la violencia tanto cuantitativamente hablando como la percibida. Específicamente Juárez se tornó en una verdadera zona de guerra durante el sexenio del presidente Felipe Calderón (2006-2012) y su desastrosa y fallida estrategia de combate al crimen organizado que provocó más de 10000 personas asesinadas en el estado. Proporcionalmente hablando, implicaría que cada chihuahuense conocía al menos a una persona asesinada en este periodo.

Ahora bien, en cuanto a la migración contemporánea y las formas en que México y El Salvador se encuentran atravesados y atravesando la misma, la desaparición de personas es un tema tan doloroso como común. El Informe de la Red de Documentación de las Organizaciones Defensoras de Migrantes ${ }^{18}$ (REDodeM, 2019) señala que las Caravanas han significado tanto una estrategia de búsqueda de sus seres queridos y de visibilización de lo atroz de esta situación, así pues estas: "han tenido presencia en México al menos desde el 2006, con el objetivo de hacer eco en la búsqueda de personas desaparecidas en situación de movilidad víctimas del crimen organizado y de la omisión del Estado [...]”, (Gómez, 2019, p. 22).

Además de una estrategia de búsqueda y denuncia por las personas migrantes desaparecidas, las caravas han sido también una estrategia de migración pues, según los datos de la misma REDODEM: "al menos 363 personas en situación de movilidad que recibieron atención de los socios de la Red mencionaron haber

18 Esta Red de organizaciones se encuentra actualmente coordinada por la Casa de Acogida, Formación y Empoderamiento de la Mujer Migrante y Refugiada (CAFEMIN), mientras que la Secretaría Técnica la atiende el Servicio Jesuita de Migrantes México. La totalidad de la Red consta de 23 organizaciones en distintos estados de la república: Chiapas, Oaxaca, Veracruz, Guanajuato, Chihuahua, Nayarit, Jalisco y Querétaro. 
llegado a México en alguna de las caravanas durante el 2019" (G ómez, 2019, p. 22). Esto es apenas un esbozo de una reflexión más profunda que no es el objetivo de este texto, pero contribuye a las premisas del mismo, sin lugar a dudas: las personas que tienen la necesidad de migrar lo hacen para preservar la vida o volverla más disfrutable, ergo, protegen y cuidan sus vidas. Migrar no es entonces un paso hacia el vacío, a la muerte, es una estrategia de supervivencia que, si bien implica riesgos que pueden llegar a provocar letalidad, se buscará minimizar dichas posibilidades con distintas estrategias de resistencia, como se ve en este caso en lo general, y como se verá en el siguiente apartado en lo particular.

Por último, respecto a los riesgos que implica la migración, la situación cada vez más recurrente es la deportación, en el informe referido se encuentra que son sobre todo hombres $(97.5 \%$ hombres y $2.3 \%$ por mujeres) los que la experimentan; el principal país de origen es Honduras, seguido por El Salvador y Guatemala. Estos procesos de deportación implican

[...] per sé la experiencia acumulada de distintas movilidades previas en el contexto de origen, luego en el contexto de emigración y en el contexto de retorno o posterior a la deportación en donde las personas se encuentran de nueva cuenta en situación de movilidad con distintos destinos posibles ${ }^{19}$ (Pinillos, 2019, p. 123).

19 Además: "Los casos de las personas en situación de movilidad con historial de deportación tanto de Estados Unidos como de México representan la acumulación de situaciones adversas y de movilidad -encerramiento (Núñez y Heyman, 2007) experimentadas en el trayecto migratorio, la prolongación de los intentos fallidos por llegar al destino planeado o deseado y el impacto de los fracasos que ello conlleva y que se condensa en las condiciones de vulnerabilidad y riesgo en las que se encuentran y con las que hacen frente en el nuevo contexto de movilidad que llevan a cabo en México" (Pinillos, 2019, p. 124). 


\section{INTERSECCIONALIDAD: UN ANÁLISIS PARTICULAR DE SALVADOREÑAS MIGRANTES EN JUÁREZ}

Usamos la palabra interseccionalidad para describir la simultaneidad de opresiones

Cherríe Moraga, 2020

Encontrarlas fue difícil. Luego de sortear múltiples veredas, se conoció de un albergue para mujeres trans en Juárez, sin embargo, la coordinadora del mismo nunca respondió mensajes ni llamadas, y cuando lo hizo, no permitió siquiera el planteamiento del proyecto, alegando que las migrantes trans albergadas ahí no querían dar entrevistas (sin consultarlas al respecto). Hasta este punto: un grupo de mujeres trans migrantes centroamericanas, en una ciudad fronteriza, sin una voz propia y sin posibilidad de escuchar de ellas mismas lo que vivían. No había acceso a otra cosa que a una "voz alta" (Bidaseca, 2011), la de la coordinadora del albergue, asumida en su representante pues, aunque es una "voz alta" de una mujer trans, esta sí tiene una nacionalidad reconocida en el lugar que habita, una identificación y un trabajo con ingreso económico. ¿Qué tipo de falacia sería la de considerar que una cuestión esencial, como ser trans, podría otorgar automáticamente la empatía, la solidaridad o la sensibilidad para reconocer las complejidades de las relaciones de poder y de interseccionalidad entre personas?

Como es posible desprender del modelo presentado como Orden de Vitruvio, la sola característica de ser mujer trans no tendría por qué asegurar trato equitativo, justo, empatía o cualquier otra forma benévola de relacionarse con las mujeres migrantes trans salvadoreñas que recurrieron a ella.

Una vez en contacto con una organización de la sociedad civil, cuyo valiosísimo trabajo se centra en la prevención de VIH/ SIDA y la reducción de contagio con población vulnerable al mismo (trabajadoras sexuales, personas adictas a drogas inyectables, entre otros), se acordó participar de sus recorridos en el centro de Ciudad Juárez para intentar localizar entre la población que atien- 
den a algunas personas migrantes para el desarrollo del proyecto de investigación.

Es otoño de 2020. Una vez en las calles del centro de Juárez, la pandemia parece una especie de bruma que se evapora bajo el sol norteño. Las trabajadoras sexuales no han cesado de laborar durante la pandemia. Mientras están ahí, esperando algún cliente, utilizan cubrebocas. Fue posible platicar con ellas gracias a la intervención de Zulema, una promotora de salud de la organización con la que se trabajó. En una de las pláticas con las trabajadoras sexuales del centro, al preguntársele si había visto en el proceso migratorio indocumentado que vivió a migrantes trans -nacionales o centroamericanas-respondió que no le tocó ver a ninguna, a pesar de haber estado un mes entero en una pequeña frontera de Sonora, esperando una oportunidad para cruzar; "cruzamos puras personas normales", terminó. ${ }^{20}$

\section{Las personas no-normales}

Dos días de recorridos en el centro de Juárez, con trabajadoras sexuales y en picaderos; y no habíamos encontrado ninguna persona trans migrante. En repetidas ocasiones nos refirieron el albergue de migrantes trans, sin embargo, tras la actitud hostil de su coordinadora, no se consideró adecuado arribar. Finalmente, una trabajadora social de la organización receptora nos contactó con una migrante trans de El Salvador que estaba con otras más. Se les planteó la posibilidad de una visita y se convino una hora para llevarla a cabo.

El marco teórico y epistemológico de la investigación ampliada, de la que este texto forma parte, asume la escucha como un lugar político en el que se potencia no solo la voz, sino un espacio de enunciación (Spivak, 2003) particular, único, creado exclusivamente para quien desea y puede hablar. La impronta esencial de este es que lo que ahí se cuenta es la experiencia personal y esta es, por sí misma, valiosa. ${ }^{21}$

20 Entrevista a A.C.T., realizada por X, en el centro de Juárez, el 20 de octubre de 2020.

21 Esta precisión se antoja oportuna pues, en el contexto internacional actual y en espacios de poder político y económico, las mujeres trans son visibles ya, aunque aún esté por valorarse si su presencia en estos espacios de toma de decisión inciden 
Una vez con ellas, emprendieron un grupo focal sin proponérselo de ese modo. Ahí contaron la serie de obstáculos que tuvieron que sortear para lograr un hospedaje que fuera digno y respetuoso, y lo consiguieron, aunque su situación es económicamente más complicada, pues ahora es completamente autogestionado. Todas hablaban al mismo tiempo y contaban una serie de experiencias dolorosas del lugar en que se albergaban anteriormente, del que escaparon. Apenas terminado este espacio, que funcionó como catarsis y contención del proceso que estaban viviendo, se les contó del proyecto de investigación y accedieron a que lleváramos a cabo entrevistas individuales sobre sus historias de vida.

Como es posible adelantar, el espacio no es suficiente para el análisis de nueve historias de vida que convergen en una experiencia migrante, por lo que se ha elegido una de ellas de acuerdo a los siguientes criterios: que representara una experiencia general (del grupo) tanto de transición (a mujer trans) como de tránsito (migración), que diera cuenta de una experiencia de vida más o menos común en El Salvador y, por último, que reflejara una forma común de adecuación en la frontera pandémica que les ha tocado habitar por los últimos meses.

Derivado de lo anterior, se comparte en este espacio la historia de Brittany, una mujer trans salvadoreña de 31 años ${ }^{22}$ que salió de su lugar de origen desde el 23 de junio de 2020, teniendo como destino Estados Unidos. Sobre su vida en El Salvador, Brittany comparte pasajes tanto felices como amargos de la misma. Su padre muere cuando ella es muy pequeña, aunque no se profundiza en este aspecto, esto la hace compartir la orfandad con toda

en mejores condiciones de vida para las mujeres trans en general. Por ejemplo, los casos de Petra de Sutter, elegida Viceprimer ministra de Bélgica (5 de octubre de 2020) o los casos de Taylor Small, la primer legisladora local transgénero en Vermont; Sarah E. McBride, elegida senadora por Delaware, lo que la convierte en la primera política transgénero con el rango más alto; incluso en los estados considerados más conservadores de Estados Unidos, como Florida, ganó una curul Michele, una mujer negra abiertamente queer. Para más, véase: https://elclosetlgbt.com/noticias/mujeres-trans-en-la-politica-petra-de-sutter-es-la-primera-mujer-trans-elegida-ministra-eneuropa/?fbclid=IwAR1MRf_CLPTjyhpIkarOIdTSqoP40HWGIdgP6I01IajGq4D0qISrKCozNOs

22 La precisión de la edad de Brittany es oportuna para ubicar su infancia en los primeros años al término de la guerra civil que se desarrolló en El Salvador de 1980 a 1992. 
una generación salvadoreña que perdió a sus padres o madres durante el conflicto armado que corrió de 1980 a 1992, y en el que se estiman alrededor de 75000 muertes, sobre todo de habitantes de las zonas rurales del país (Ward, 2013). Este evento marcaría la vida de Brittany no solo con la pérdida, sino con una serie de consecuencias económicas y sociales que se relacionan de forma compleja con el hecho de que ella nunca se sintió como un niño, aunque ese haya sido el género asignado al nacer y con el que fue leída durante toda su infancia. Una mujer trans que nace en los últimos años de una guerrilla que asoló su país durante más de 10 años.

Brittany apoyó a su mamá en el comercio informal, vendiendo prendas íntimas. Con un gesto estirando su brazo, ella recuerda cómo este estaba todo lleno de ropa interior colgada sobre él, para mostrársela a las posibles compradoras cada que su mamá se lo indicaba. Mientras cursaba educación básica, recuerda el momento en el que consiguieron hogar en unos proyectos en las afueras del pueblo, cerca de un basurero. Es un recuerdo bastante triste, a Brittany se le salen las lágrimas. La pandemia que atravesamos insta a que constatemos la empatía de otros modos, a pesar de la distancia corporal.

La tristeza profunda del recuerdo tiene que ver con el hecho de que, en ocasiones, cuando la necesidad les obligaba, salían a buscar algo que pudieran comer a ese basurero. Sin embargo, como una operación esperanzadora de la memoria, Brittany comienza a contar otras experiencias de ese tiempo: “íbamos al río, y jugábamos todos los vecinos y así, había una quebrada, y nos íbamos por toda la quebrada, a conseguir pollos y así", para ella, esa ya era una mejor época, que perduró hasta los 10 u 11 años, momento en el que decide irse a San Salvador: "con mi abuela, para tener una mejor vida”. Ahí su abuela tenía un negocio de comida y Brittany le ayudaba a atenderlo, y se le pagaba por ello. Aunque sus ingresos eran pocos, se compensaba al no pagar alquiler. Estuvo así hasta los 17 años, estudiando y trabajando, ella misma resolvía todos los gastos relacionados con sus estudios. Inició una carrera universitaria, quería ser maestra, luego por circunstancias que no 
precisa, deja la carrera, "Decidí emigrar para tener una vida mejor de la que había tenido" dice finalmente al cerrar lo referente a esta etapa de su pasado (Brittany, 2020). Aunque el acceso y cursada de la universidad puede considerarse como una condición de privilegio, algo que no mucha gente podría alcanzar en su país, no era vivido así por Brittany, que sabía que no podría ser ella misma desempeñándose en esa profesión (como maestra). Son reiteradas las ocasiones, durante el relato, en las que ella precisa lo conservadora que es la sociedad salvadoreña, que excluye a los hombres homosexuales y mucho más a una mujer trans.

En el ánimo de hurgar un poco en el ejercicio ontológico que significa la transición, se le pregunta a Brittany cómo eligió su nombre. Ella responde que es algo que pensó mucho y que finalmente definió a partir de una película que se titula ¿Dónde están las rubias?, en ella aparecía un personaje con ese nombre y a ella le pareció con mucha sofisticación, “era de las más sofisticadas en esa película”, y es lo que la lleva a elegir ese nombre. Brittany no es el único caso en estas historias de vida que elige su nombre a partir de un personaje, y tiene que ver con los atributos y forma de ser del personaje en cuestión, o lo que el nombre representa. Es decir, no es el nombre en abstracto, sino como significado de un alguien con quien ellas se sienten identificadas.

Brittany siempre supo que le gustaban los niños. Su primer beso ocurrió a los 15 años, con un novio de entonces, otro adolescente como ella. Cuenta que, aunque de niña no tuviera ni una mínima noción de morbo ni supiera nada respecto a relaciones sexuales o cualquier situación erótica, cuando veía revistas, ella miraba a los hombres, "no con aquel morbo, solo los miraba porque me gustaban, pero no con ese morbo ¡solo los miraba!" (Brittany, 2020). La explicación de Brittany respecto a la carga de morbo que pudo haber habido en el descubrimiento de que veía más a los hombres en las revistas, puede relacionarse con toda la serie de prejuicios que se han construido respecto a la población trans y homosexual, respecto al desarrollo y descubrimiento de su sexualidad y sus expresiones, es por ello que ella siente la necesidad de aclarar su sexualidad como un proceso. 
Mientras estuvo en San Salvador, ella performó ${ }^{23}$ como un hombre homosexual, incluso al momento de emigrar lo hizo como un hombre. Fue hasta el encuentro con las compañeras con las que ahora habita que definió que eso no era todo lo que era, sino que era una mujer trans. Así pues, fueron la vida y las experiencias colectivas las que potenciaron la emergencia del ser que siempre había sido, para explicar esto anota: "lo que pasa es que en El Salvador hay mucha discriminación y hay mucha transfobia [...] nunca me atreví a hacerme un proceso como trans porque yo miraba a las chicas que se atrevían y sufrían mucha discriminación y a lo que acudían era a la prostitución la mayoría porque no había oportunidades de empleo, entonces esa parte me daba temor" (Brittany, 2020). Y el temor no es para nada infundado, México, que puede considerarse un lugar menos hostil respecto al contexto centroamericano para las personas trans, aún dista mucho de ser un espacio seguro para ellxs. ${ }^{24}$ Brittany termina elaborando una proyección de lo que le hubiera ocurrido si se quedaba a vivir como mujer trans en su país: “... y una trans más muerta y eso era todo, entonces a mí me daba miedo" (Brittany, 2020).

Ella comienza a transicionar ya en México. Entre las cosas que descubre es que luego de la transición ya no hay más posibilidades de solo vestirse como mujer pues "trans duerme como chica y amanece como chica", y concluye que "ser trans es aceptarse tan cual una es". Sin embargo, como la transformación profunda que

23 Para Butler, género es una forma de desposesión que no podemos controlar absolutamente y que siempre nos antecede. Por lo tanto no es una descripción, sino una prescripción, una normatividad, un performance. Las identidades son entonces prestadas, impuestas (Butler, 1990). Por su parte Paúl B. Preciado, al exponer su noción de "contrasexualidad", establece que esta es un "análisis crítico de la diferencia de género y de sexo, producto del contrato social heterocentrado, cuyas performatividades normativas han sido inscritas en los cuerpos como verdades biológicas" (Preciado, 2011, p. 12).

24 Por ejemplo, en el último año se reportan mujeres trans desaparecidas en Jalisco; una médica trans con alto reconocimiento en la vida pública y política del país es asesinada, así como una activista trans de Tijuana. Para más, véase: https:// www.infobae.com/america/mexico/2020/10/02/la-reciente-ola-de-violencia-contra-lacomunidad-lgbtq-en-jalisco-ha-dejado-tres-mujeres-trans-desaparecidas/ , https:// www.eluniversal.com.mx/nacion/lamentan-muerte-de-doctora-trans-y-activista-mariaelizabeth-montano y https://www.milenio.com/estados/matan-activista-transgenerotijuana-baja-california. 
es, ella aún no le cuenta a su familia (mamá y hermana) "que se hizo chica trans", "yo espero estar como que estable para poder ya... 'no me digan nada porque ya estoy estable, ya me puedo mantener' o algo así" (Brittany, 2020).

A la pregunta de cuál es el mejor escenario para ella, comenta que espera que se termine "todo esto", refiriéndose a los meses de espera en Juárez y al mismo final de la pandemia, agrega que ella lo que busca es "cumplir con mis objetivos y mis sueños, y ya tener una vida estable y llegar como al final de todo este camino que he ido recorriendo, desde que salí, y además precisa que "al final del día se me cruzan pensamientos de que lo importante es cómo yo me sienta, llegar a mi colonia y decir: soy esta" (Brittany, 2020).

Tanto la de Brittany como el resto de historias de vida tienen en común el miedo que experimentan al salir a la calle, aparece como una cosa menor el que la gente hable de ellas o las critique, pero es claro el miedo a las agresiones físicas; además de las experiencias que hayan vivido de agresión, es clara la influencia que tuvo el discurso de odio y de siembra de temor que experimentaron con la coordinadora del albergue en el que estaban antes que, entre otras cosas, les aseguró que si salían a la calle en Juárez, las matarían por ser trans y migrantes.

A pesar de todo, este miedo se ve superado cuando las salidas son en colectivo. Es decir, el grupo como un hálito de potencia para ellas. Brittany dice: "[...] a veces salgo con temor a la calle, de que me vayan a dar un balazo o algo, porque hay gente que odia a las trans, que es homofóbica [...] salir y verme así bien divina, pero hay gente que no le gusta [...] entonces yo a veces sí salgo con seguridad cuando vienen mis amigas, salgo con seguridad de salir” (Brittany, 2020).

\section{CONCLUSIONES}

Las resistencias al Orden de Vitruvio son, hasta ahora, colectivas. ¿Es que puede haber una estrategia individual que combata la insaciable y monstruosa combinación del sistema heteropatriarcal, capitalista y colonial? Este grupo de mujeres trans migrantes que 
escaparon de $\mathrm{G}^{25}$ y se organizaron a vivir en un hotel que tenía más de 20 años abandonado en el centro de Juárez son una representación de la potencia que pueden alcanzar juntas, para resistir. Es en esta colectividad que ellas van trazando un modelo de nombrar propio, llamarse entre ellas por los nombres que han elegido, reconocerse las que son entre ellas mismas al grado de que la presencia de las otras reafirma la propia presencia (y existencia).

Las operaciones de resistencia son aquellas que encaminan al regreso al centro, a ese espacio de ejercicio de derechos, de reconocimiento que, per se, ocupa el hombre de Vitruvio. Estas no son unidireccionales, constantes ni evidentes. Pueden ocurrir de múltiples formas y se aprehenden en cuanto a la potencia que permiten a las personas subalternas, potencia que ocurre en la construcción de un cotidiano colectivo.

En este grupo de mujeres trans se encuentran reivindicaciones de todo tipo. Las primeras y recurrentes en todas son las referentes a reivindicar quiénes son y las razones que tienen para presentarse a sí mismas, y quienes las rodean, tanto con los nombres que han pensado y construido, con los que se sienten identificadas, como con la ropa que quieran utilizar, con la que quieran brillar pues; al final de cuentas, aquí en la frontera, aún desenraizadas de la tierra en la que nacieron y crecieron los primeros años de su vida, solo están floreciendo.

\section{REFERENCIAS BIBLIOGRÁFICAS}

Agamben, G. (2015). ¿Qué es un dispositivo? Anagrama.

Bidaseca, K. (2011). Mujeres blancas buscando salvar a las mujeres color café de los hombres color café. O reflexiones sobre desigualdad y colonialismo jurídico desde el feminismo poscolonial. En K. Bidaseca y V. Vázquez-Laba (Comps.). Feminismos y poscolonialidad. Descolonizando el feminismo desde y en América Latina (pp. 95-120). Godot.

Brittany. (21 de octubre de 2020). Entrevistas H.O. (N. CastorenaSáenz, Entrevistador).

25 Coordinadora del albergue Respetttrans. 
Butler, J. (1990). El género en disputa. La subversión de la identidad. Editorial Paidós.

Butler, J. (2006). Vida precaria. El poder del duelo y la violencia. Editorial Paidós.

Butler, J. y Spivak, G. (2009). ¿Quién le canta al estado-nación? Lenguaje, política, pertenencia. Editorial Paidós.

Cortina, A. (2017). Aporofobia, el rechazo al pobre. Editorial Paidós. De los Ríos, A. (2014). Militancia, testimonio y violencia. Revista de psicología Iztacala, 17(1), 344-364.

De Beauvoir, S. (2012). El segundo sexo. Random House.

Deleuze, G. (2002). Diferencia y repetición. Amorrortu Editores.

Deleuze, G., y Guattari, F. (2015). Mil mesetas. Capitalismo y esquizofrenia. Pre-Textos.

Despentes, V. (2018). Teoría King Kong. Random House.

Drullard, W. (12 de noviembre de 2020). Complicidad colonial:

el racismo estructural y la feminidad blanca. El Salto Diario. https://www.elsaltodiario.com/mapas/complicidad-colonial-elracismo-estructural-y-la-feminidad-blanca.

Echeverría, B. (2010). Modernidad y blanquitud. Era.

Gómez, L. (2019). El desasosiego llamado México. Personas no nacidas en México, en tránsito dentro de México hacia Estados Unidos y otros países. En REDODEM, Informe 2019 (pp. 20-39). REDODEM.

González Herrera, C. (2008). La frontera que vino del norte. Santillana/El Colegio de Chihuahua.

Kobabe, M. (2020). Género queer. Una autobiografía. Astronave. Lerner, G. (1986). La creación del patriarcado. Katakrak Liburuak. Lotman, I. (1996). Semiosfera I. Semiosfera de la cultura y del texto. Cátedra.

Menjívar, R. (2018). El Salvador: El eslabón más pequeño (1979). En L.M. Castro y R.O. López Salazar (Coords.). Antología del pensamiento crítico salvadoreño contemporáneo (pp. 17-32). CLACSO.

NPR. (2020). The Modern White Power Movement [episodio de podcast]. En Throughline, https://open.spotify.com/episode/5I4 FGD0FPIWDgI9OKCnIt2?si=dgidIC1IR0WzHYTqOYVkEw. 
Oficina de las Naciones Unidas Contra las Drogas y el Delito (2009). Reporte Global. Informe de Globalización del crimen.

Pinillos, G. (2019). Precariedad y vulnerabilidad tras la experiencia de deportación en el tránsito por México. En REDODEM, Informe 2019 (pp. 122-152). Redodem.

Prado, R. E. (abril de 2018). El entramado de violencias en el Triángulo Norte Centroamericano y las maras. Sociológica, 33(93), 213-246. http://www.scielo.org.mx/scielo.php?.script=sci_arttex t\&pid=S0187-01732018000100213

Preciado, P. B. (2011). Manifiesto contrasexual. Anagrama.

Red de Documentación de las Organizaciones Defensoras de Migrantes. (2019). Informe 2019. REDODEM.

Sassen, S. (2003). Contrageografías de la globalización. Género y ciudadanía en los circuitos transfronterizos. Traficantes de sueños.

Scott, J. C. (2005). Los dominados y el arte de la resistencia. Era. Selva-Sutter, E. (2018). Un acercamiento a la interacción de la pobreza, la desigualdad, la desnutrición, el neoliberalismo y la salud en América Latina, desde el punto de vista del pensamiento complejo. En L.M. Castro y R.O. López Salazar (Coords.). Antología del pensamiento crítico salvadoreño contemporáneo (pp. 269-306). CLACSO.

Spivak, G. C. (Enero-Diciembre de 2003). ¿Puede hablar el subalterno? Revista colombiana de Antropología, 30, 297-364.

Valencia, S. (12 de octubre de 2020). El transfeminismo no es un generismo. Parole de queer. https://paroledequeer.blogspot. com/2020/10/sayak-valencia-transfeminismo.html?fbclid=IwAR OH9EEVoHQdAUQBmOPvo3dDjReKcGpV-aslc9GLUaKVRT5TGxG2cDcK4Vk

Ward, T. (2013). Gangsters Without Borders. An Ethnography of a Salvadoran Street Gang. Oxford University Press. 